Corresponding author Phone +421556022920 E-mail address: jozef.bocko@tuke.sk (Jozef Bocko, prof. Ing. CSC)

Article information Article history: AMS-Volume15-No.4-00130-11 Received 23 March 2011 Accepted 26 May 2011

\section{Application of Computational Methods and Methods of Experimental Stress Analysis for Determination of Lifespan of Pipe Yards}

\author{
František Trebuňa, Jozef Bocko*, Ingrid Delyová, Peter Sivák \\ Department Department of Applied Mechanics and Mechatronics, Faculty of Mechanical Engineering, Letná 9, 04200 Košice, \\ Slovak Republic
}

\section{BIOGRAPHICAL NOTES}

František Trebuňa, Dr.h.c. mult. prof. Ing. CSc. is a professor of applied mechanics, Head of the Department of Applied Mechanics and Mechatronics and Dean of the Faculty of Mechanical Engineering. He is author of 10 monographs, 12 university textbook, special book publications, 12 university notebooks and more than 300 publications in journals and conference proceedings at Slovakia abroad. He is author of important projects and engineering works. He received several prizes at home and abroad. He received three titles Doctor Honoris Causa (DHC) including two from foreign universities for the development of applied mechanics and mechatronics.

Jozef Bocko, doc. Ing. CSc. is an associated professor of applied mechanics on the Department of Applied Mechanics and Mechatronics, vice-dean of the Faculty of Mechanical Engineering. He is author of 1 monograph, 2 university textbooks and more than 90 publications in journals and conference proceedings at Slovakia and abroad. His research interests are oriented to the field of the finite element method, shell theory, nonlinear mechanics and application of Lie group theory in mechanics. He worked on several grant projects and research works for practice.

Ingrid Delyová, Ing. PhD. finished her engineering level education on the Faculty of Mechanical Engineering, Technical university of Košice at 2002. She gained PhD. at the field of Applied mechanics at 2005 on the Faculty of Mechanical Engineering, Technical university of Košice. At the present time she works on the Department of Applied Mechanics and Mechatronics, Faculty of Mechanical Engineering, Technical university of Košice as an assistant. She is an author of 2 textbooks and more than 20 papers in domestic and foreign journals and conference proceedings oriented to the problems of lifetime assesment of structures by means of the methods of EAN. She worked on several grant projects and research works for practice.

Peter Sivák, Ing. PhD. finished his engineering level education on the Faculty of Mechanical Engineering, Technical university of Košice at 1986. He gained PhD. degree at the field of Applied mechanics on the Faculty of Mechanical Engineering, Technical university of Košice at 2007. At the present time he works on the Department of Applied Mechanics and Mechatronics, Faculty of Mechanical Engineering, Technical university of Košice as an assistant. He is an author of 1 monograph, and more than 40 papers in domestic and foreign journals and conference proceedings oriented to the problems of experimental stress analysis. He worked on several grant projects and research works for practice. 


\section{KEY WORDS}

Pipe Yards, Fatigue, Experimental Stress Analysis

\section{ABSTRACT}

Compressor stations and their pipe yards are technological complexes that are loaded by dynamic loading during their operation. The result of such loading can be fatigue failure of structural member or whole system with serious consequences. One possibility of decreasing disadvantageous dynamic loading and increasing of lifespan is using vibroinsulation elements. The lifespan of structure is intimately connected to critical locations as pipe joints realized by welds. Residual lifespan is expressed on the basis of data gained by experiments according to appropriate standards.

\section{Introduction}

Pipe yards of compressor stations are part of technological equipment of strategic importance for the transport and distribution of gas. Gas pipelines of compressor stations are composed of complex technological net of crossing overground and underground pipes (Figs. 1 and 2) that are exposed to diverse dynamic stress phenomena. Pipe systems have to be carefully checked from the point of their reliability because their failure can threaten human lives, to cause serious ecological catastrophes and heavy economic losses.

\section{Structures of pipe yards and their loading}

The pipelines are typically loaded by pulsations of pressure (surging) and whistle effects. The reason of pulsations in pipe system of compressor station is non-stationary flow through some devices that is a result of unsuitable distribution of flow in pipe system and resulting increase of resistance, shifting of operation point of these devices to the boundaries of dynamic stability. The main reason of such phenomenon can be inappropriate arrangement of individual devices. Vibration of pipeline with low frequency in the level of some $\mathrm{Hz}$ resulting e.g. due to two steps gas boosting results to vibration of valves and for more intensive vibration during time period longer than 15 minutes it can cause damage of fittings of pipe yard. The surging is a non-stationary phenomenon that arises during operation of turbo-compressor and it is a result of flow interaction inside of pipeline system. During surging occurs periodical flow

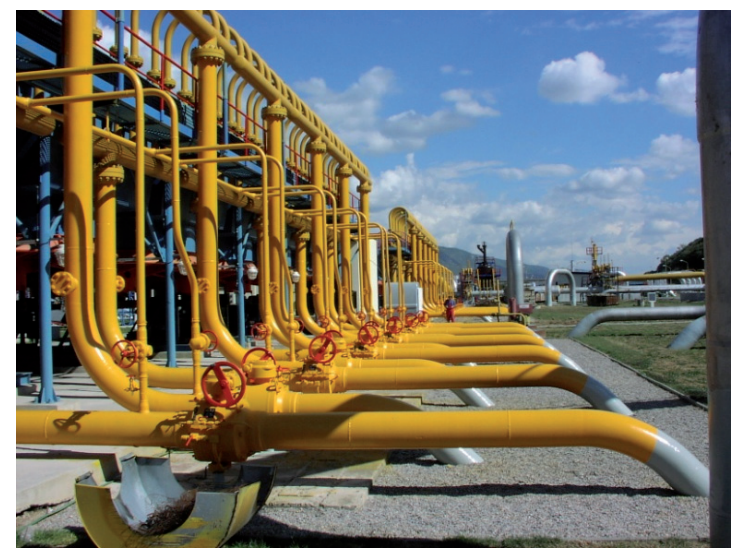

Fig. 1: Pipe yard of compressor station.

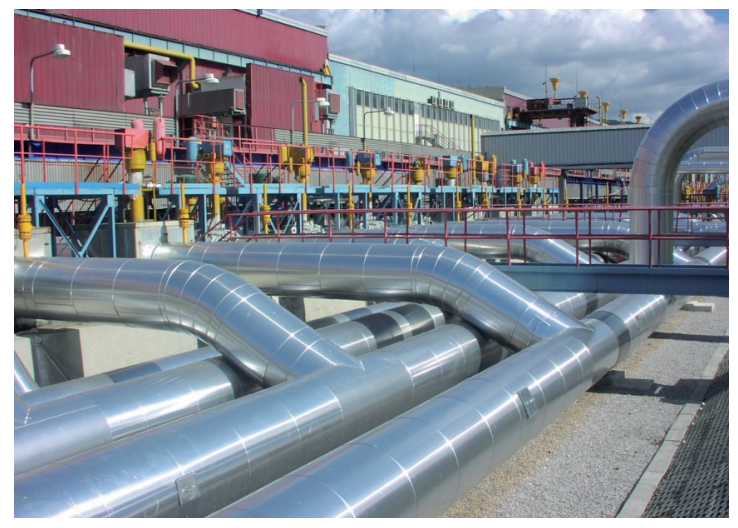

Fig. 2: Pipe yard with pipes of suction, medium pressure and discharge.

change in turbo-compressor and in connected pipe net. Non-stationary phenomena in pipeline system arise also due to so-called whistle effect that is a result of Helmholtz steady oscillations in the locations of connection of valves and closed branches, where arises disturbing flow field. Beside of this, in every pipe system occurs during its operation time-dependent loading, e.g. during starting or finishing its operation, changes of pressure from technological reasons and so on, that can lead during long-time operation to fatigue failure of material and in case of exceeding of lifespan to its damage. Assessment of fatigue lifespan of critical segment of working pipe is possible if we know the shape of investigated section, its dimensions, mechanical properties of material, real operational load, history of pipe loading and corresponding information about random loading. Pipe yards belong to the group of technological carrying structures that are designed 
in accordance with Standard STN EN 1993 - Eurocode 3. Design of steel structures. These Standards are used also later in the phase of strength check, for assessment of failure states and verification of safety after certain period of operation, for assessment of fatigue level, or after general overhaul. The lifespan analysis has to be accomplished for such critical elements, structural members, and critical locations that are supposed to be critical for lifespan of the whole structure. Critical are locations of pipe joining in saddles, where due to several years dynamic loading and vibrations occurred failures. Accordingly there was provided measurement and lifespan assessment of pipeline systems on two compressor stations with turbo-compressors with power $6 \mathrm{MW}$. At the investigated section of pipe yard KS 1 were used vibroinsulation elements (steel dampers) on the pipe base, Figs. 3 and 4.

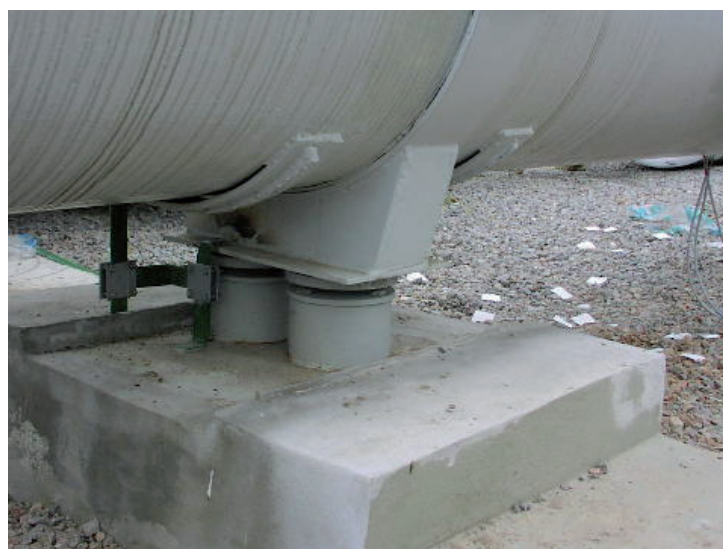

Fig. 3: Base of pipe with vibroinsulation elements.

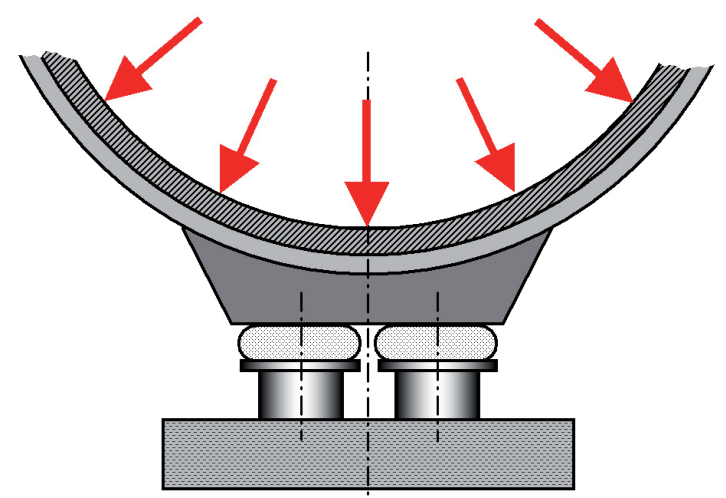

Fig. 4: Integration of vibroinsulation elements into base of pipe.

The pipes of pipe zard KS 2 are without of vibroinsulation elements. The main reason for using vibroinsulation was the aim to remove dynamic loading in order to decrease loading of pipeline system and at the same time to prolong its lifespan.

\section{Data collecting about pipeline loading}

During the investigation was applied the combined method of experimental and analztical determination of operational loading (resulting internal forces) due to random loading prosecc in the chosen location (cross-section) of pipe that was verified many times in practice. Basic principle of this method was used for datermination of internal force quantities in pipe yards. The principle was later enhanced in order to allow creation of complex view about possible dangerous loadings in locations of supports, concentrators and branches of pipe yard. At the same time were considered operational influences of random process of loading to the resulting stress and to assessment of residual lifespan of pipe yards. On the basis of this method there were realized experimental measurements on the basis of electrical resistance strain-gage method. Applied measurement chain had configuration according to Fig. 5. The measurements were realized on the discharging pipe with a branch while three cross-sections, signed as A, B, and C, Fig. 6, with applied strain-gage rosettes, separated the section of pipe with base containing elastic vibroinsulation elements on KS 1 and without Vibroinsulation element on KS 2. Strain-gage measurements were accomplished at different time periods. In Fig. 7 is a view to uncovered part of pipeline and on Fig. 8 is a detail of applied straingage rosettes [4], [5].

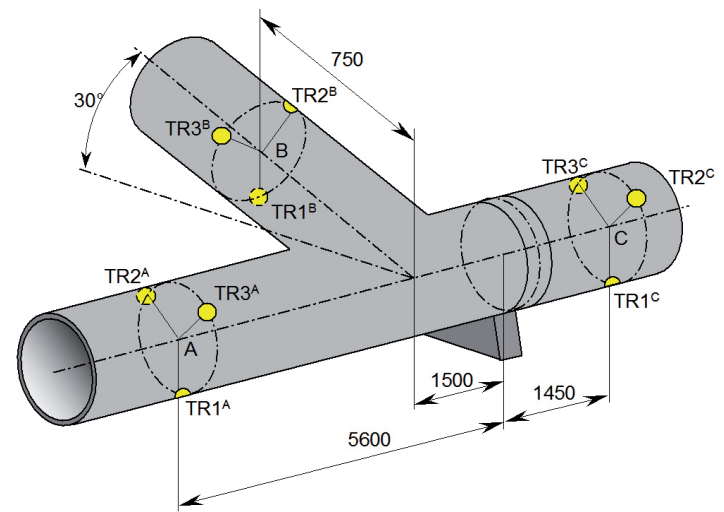

Fig. 6: Location of strain-gages on the pipe of discharge with a branch. 
Acta Mechanica Slovaca

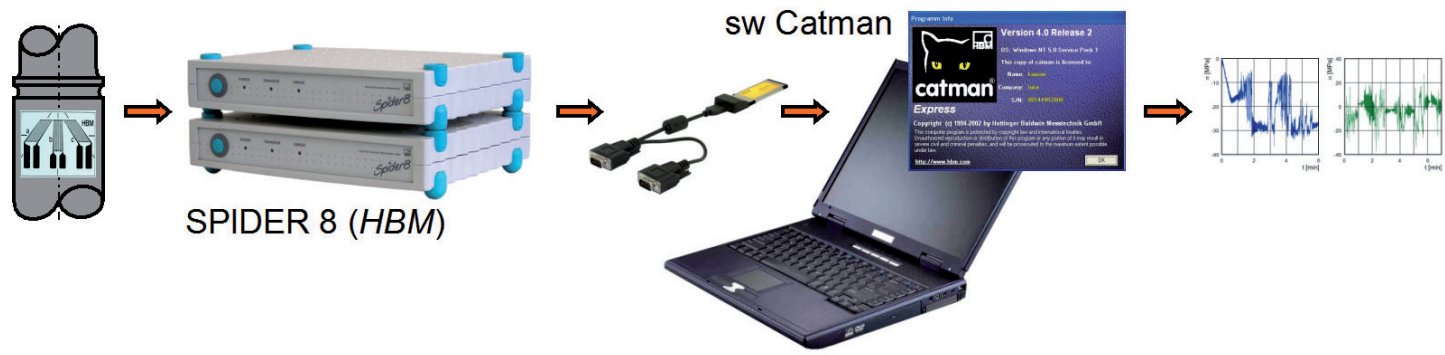

Fig. 5: Strain-gage measurement chain.

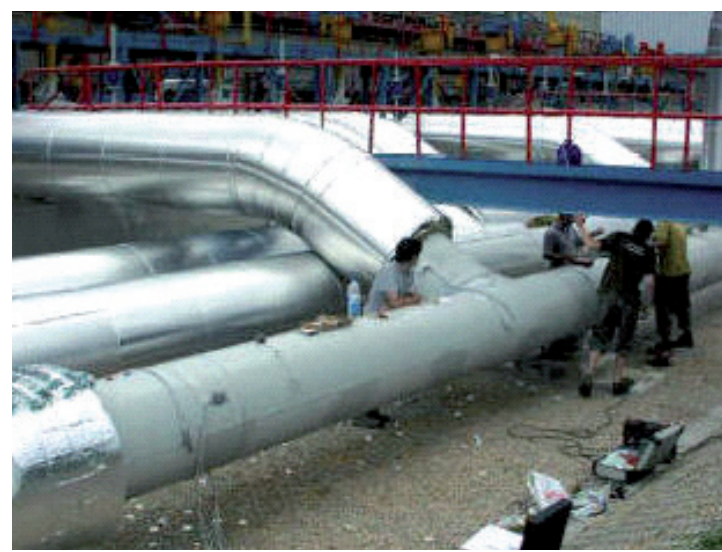

Fig. 7: Uncovered part of pipeline.

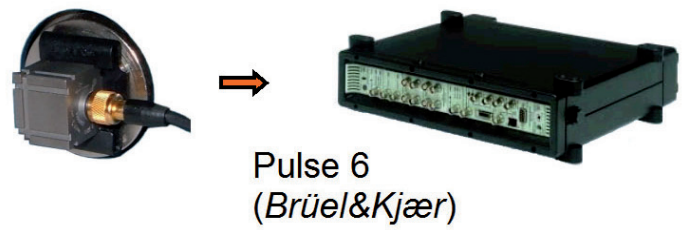

Fig. 9: Chain for measurement of mechanical vibration.

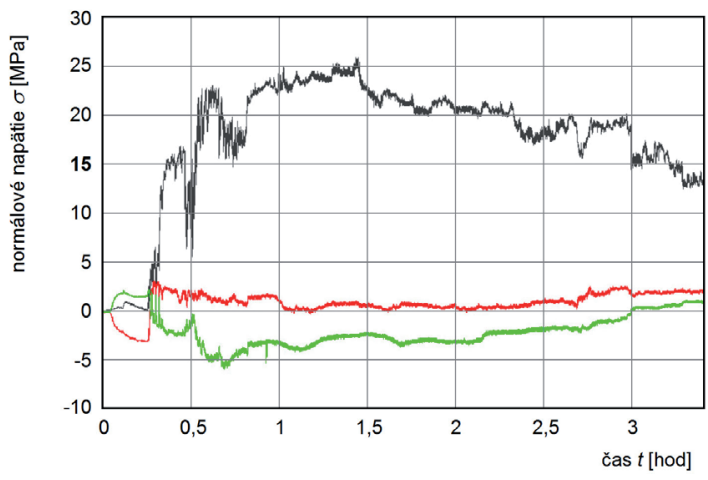

Fig. 10: Example of charts of measured normal stresses in location A.

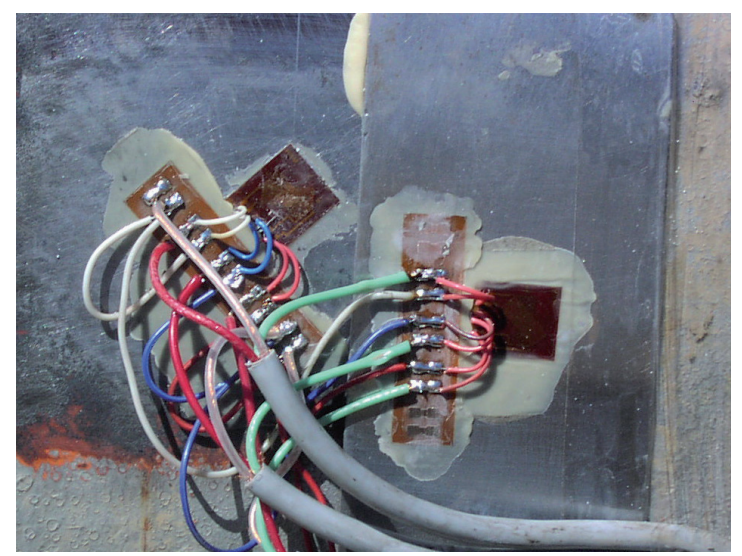

Fig. 8: Detail of applid strain-gage rosettes.
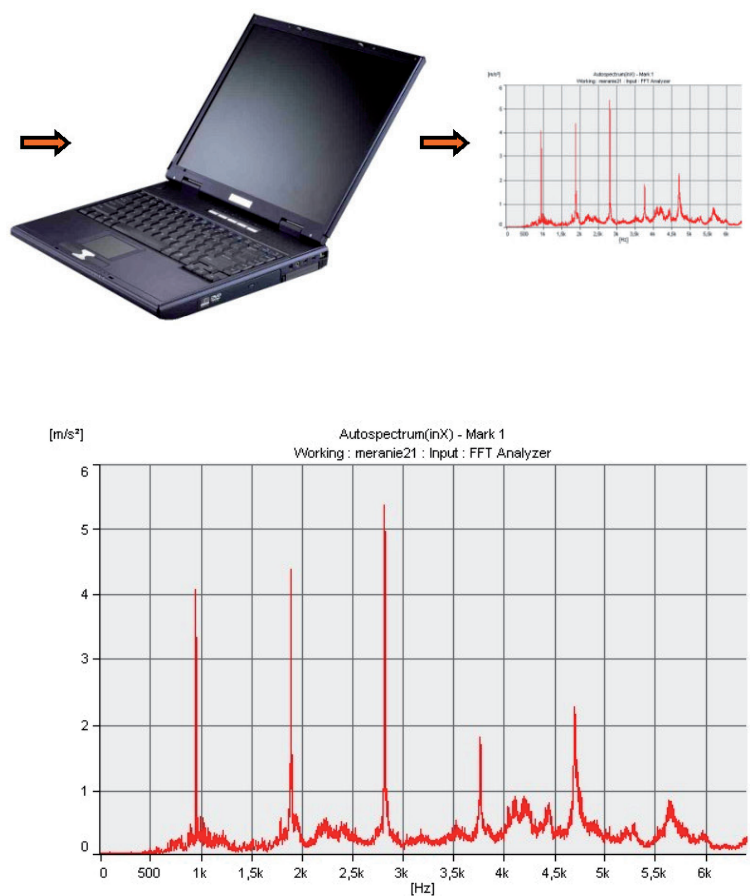

Fig. 11: Example of chart of measured frequency dependence of accelerations on a base. 
The information about relevant stress amplitudes had to be connected with dynamical effect during operation. It was the reason why the stress changes determined by strin-gages were verified by dynamic parameters - time and frequency dependent accelerations gained from measurements of mechanical vibration by the PULSE 6. Corresponding measurement chain had configuration according to Fig. 9. Examples of gained charts are given in Fig. 10 and 11.

Strength and lifespan of investigated pipeline systems was closely tied to further critical locations of structure, e.g. joints of pipes realized by welds. In order to investigate degradation changes of material properties after long-term operation there were accomplished destructive and nondestructive analyses of material. In case of destructive analysis was taken a specimen from the critical location and consecutively it was tested according to the Standards that were valid at that time. Mechanical and technological properties of material were verified by the tensile test, by the impact test of bending under temperature $0^{\circ} \mathrm{C}$ and by test of brittleness under low temperatures. If possible, the results were compared with data given by producer. At the same time metallographical analysis was realized for determination of material structure [2]. If there were problems with taking specimens, the harness test with Poldi hammer was performed in order to determine standard static tensile toughness. The welded joints used in the pipeline were from the point of view of structure, hardness, fracture toughness and brittleness under low temperatures considered as meeting the requirements. Statical levels of stresses were in computations of lifespan incorporated as residual stresses. They were detected by the methods of experimental stress analysis - by the hole-drilling method based on strain-gage measurements according to Standard ASTM E837-01 using system RS 200 [3]. The measurement chain had configuration according to Fig. 12.

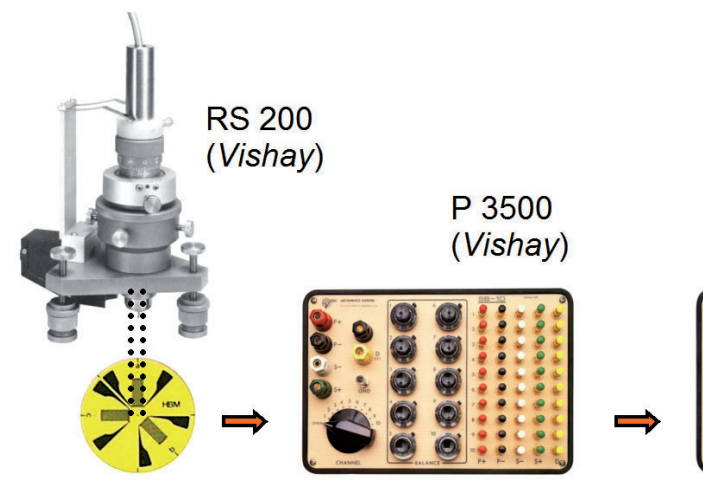

Fig. 12: Measurement chain of the hole-drilling method for the measurement of residual strains.

\section{Assesment of residual lifespan of pipeline}

For the assessment of residual lifetime of pipe yards KS 1 and KS 2 was applied procedure according to Standard STN EN 1993-1-9 - (Eurocode 3. Design of steel structures. Part 1-9: Fatigue). The welds used for pipe yards KS 1 and KS 2 were for the analysis considered as structural detail, more specific, as welded joint detail, with crosswise butt weld, welded from both sides, elaborated under flux, with coarse surface without outer defects.

With respect to the plane stress state, it was necessary to use the theory of strength for a material in ductile state. Precondition for its application was that individual components of gained stresses were not phase-shifted. Corresponding values of equivalent stresses were determined by von Mises theory. Such values were finally used for assessment of fatigue for loading of structural detail with constant stress amplitude. All computational relations and corresponding algorithms were incorporated directly into programs for processing of measured data. The results are given in Tab. 1 [6], [7].

Whole process of assessment of pipe yards KS1 and KS2 from the point of view of fatigue and used methods of random loading processing respected to the whole extent orientation, technical equipment, practical opinions and scientific potential of Department of Applied Mechanics and Mechatronics, Faculty of Mechanical Engineering, TU Košice. 
Table 1: Overall results.

\section{Structures of pipeline systems of compressor stations}

Equipment or structure (investigated element or structural member)
Reason for determination of cumulation of fatigue failure and prediction of fatigue lifespan
Specific operational conditions and other conditions of measurement
Results and recommendations of expert examination

Resulting from analysis according to current standards rejection of influences of cumulation of fatigue failure (lifespan without limits) due to decrease of maximum stresses by cca $40 \%$

Assessment of residual lifespan of system after more than 25 year operation in case without using vibroinsulation elements
Considerable influences of pressure pulsation, surging and whistle effects case of using vibroinsulation elements
Pipe system (yard) of compressor station KS 2 (pipes of suction, medium pressure and discharge)

\section{Conclusion}

By the comparison of maximal normal stresses measured during start of compressor KS $2\left(\Delta \sigma_{\max }\right.$ $=82 \mathrm{MPa}$ - pipe without vibroinsulation elements) and $\mathrm{KS} 1\left(\Delta \sigma_{\max }=52 \mathrm{MPa}\right.$ - pipe with vibroinsulation elements) was found out that the maximal normal stresses decrease by approximatelly $40 \%$, which indubitably affirm decreasing of dynamic loading and increasing of residual lifespan of pipeline due to application of elastic bases. In case of compressor station KS 1 in accordance with the corresponding Standard was not necessary to take into account fatigue because of low stress amplitudes. Accordingly, under some circumstances it is a structure with unlimited lifespan, i.e. the structure is without limit state of fatigue.

\section{Acknowledge}

The paper was created in the frame of project "Center for research of control of technical, environmental and human risks for permanent development of production and products in mechanical engineering" (IMTS:26220120060) on the basis of operation program Research and development supported by European Regional Development Fund and project VEGA 1/0265/10.

\section{References}

[1] LAERMANN, K., H.: On Necessity and Possibility to Fully Exploitation of the Entire Information Inherent in Structural
Analysis Data. Acta Mechanica Slovaca. Volume 14, No. 4, 2010, pp. 6-15. ISSN 1335-2393.

[2] ŠIMČÁK, F., BERINŠTET, V., ŠTAMBORSKÁ, M.: Some Possibilities of Determination of Yield Conditions for Cold Rolled Steel Sheets. Acta Mechanica Slovaca. Volume 14, No. 4, 2010, pp. 28-35. ISSN 1335-2393.

[3] TREBUÑA, F., ŠARGA, P.: Using of Program MEZVYNA for Measurement of Residual Stresses to Solving Practical Problems. Acta Mechanica Slovaca. Volume 15, No. 2, 2011, pp. 14-20. ISSN 1335-2393.

[4] TREBUŇA, F., a kol.: Určenie zvyškovej životnosti potrubných dvorov. Priebežná a záverečná správa IV. etapy. Výskumná správa, SjF TU Košice, 2004. 178 s.

[5] TREBUŇA, F., a kol.: Určenie zostatkovej životnosti potrubného dvora prvej haly kompresorovej stanice vo Velkých Kapušanoch. Výskumná správa SjF TU Košice, 1999. 456 s.

[6] DELYOVÁ, I.: Uplatnenie prostriedkov EAN pri určovaní životnosti nosných prvkov a konštrukcií. Doktorandská dizertačná práca. KAMaM SjF TU Košice, 2005. 100 s.

[7] OSTERTAG, O., SIVÁK, P.: Degradačné procesy a predikcia životnosti. TU SjF Košice, 2010. 225 ISBN 978-80-553-0486-1 